\title{
Promises and Environmental Risks of Digital Advertising
}

\author{
Advertising is the web's main funding model, \\ and has shaped it in its image. As well as funding \\ products and services, advertising also funds hate \\ speech and disinformation, while contributing \\ to overconsumption. This paper calls for policy \\ interventions which address these shortcomings. \\ By Harriet Kingaby
}

D igital advertising is a booming industry, which is rapidly incorporating Artificial Intelligence (AI) into its technological mix. Advertising subsidises products and services, but it also creates funding models for hate speech and disinformation, while contributing to overconsumption. The integration of AI presents its own issues: Environmental protection and human rights are frequently not considered, or considerations are overridden by commercial concern. The most alarming threat, however, is how both advertising and AI enable the spread of climate mis- and disinformation throughout the web. This paper calls for policy interventions which centre mis- and disinformation and learn from offline Planning and Environment laws. In all cases, interventions must consider the systemic effects on the web from digital advertising itself.

\section{The rise of digital advertising}

Digital advertising is a booming industry, growing from 162 billion USD in 2015 to 333 billion USD in 2019 (Enberg 2019), making it the primary business model sustaining the web. As with many other industries, the digitalisation of advertising has created side effects that go far beyond ad-revenue and the advertising sector. Until the mid-2010s, legislation, guidance and regulation had focused on the content and messaging contained within adverts themselves. However, the process of buying and selling advertising online is shaping the development of our online spaces, and seriously impacting individuals and societies.

In the past five years, digital advertising has been implicated in some of the more troubling offline events that result from our race to get online. Shoshana Zuboff (2015) dubbed the data harvesting and processing techniques which have come to define our relationship with many tech companies, advertisers, and publishers, as 'surveillance capitalism' (the commodifica- tion of personal information). Meanwhile, Tim Berners-Lee has warned of the "perverse incentives" (commercial incentives which have little to no user benefit) created by ad-reliant business models that shape the internet as we see it today. These incentives have fundamentally changed the way information is presented by our media and led to addiction-based design to be incorporated into platform design (Orlowski 2020).

On one hand, advertising funds the online content, services and journalism that make the internet accessible for the masses, on the other, advertising can degrade user experience, discriminate against marginalised communities, and create a funding model for the hate and disinformation which threaten democracies and our environment (Avaaz 2019). The sheer opacity of the internet and its obsession with performance metrics is allowing it to be exploited by fraudsters, hate preachers and opportunists peddling disinformation.

„Large parts of the adtech industry operate in the shadows ... This creates a significant power asymmetry, where any given adtech company may be armed with thousands of data points about an individual and a large arsenal of insights derived from behavioural psychology, while the individual has no idea about the company even existing" (Forbrukerrådet 2020).

Regulation of this sector has been slower than the adoption of the technology itself, in part due to the complicated nature of the technology itself and complicated language surrounding it. This lag has embedded behaviours and precedents which are contrary to consumer protection best practice, and do not live up to advertisers' purported brand values.

\section{Artificial Intelligence in digital advertising}

Algorithmic decision-making has been used in advertising for over a decade, and a mainstream adoption of Artificial Intelligence (AI) is imminent according to a recent survey by Statista. Only $15 \%$ of US advertisers were using some form of AI in 2018 but use of the technology was predicted to grow by 149\% in 2020 (Guttmann 2019), even if those advertisers suspected that the hype around the technology currently outweighs the actual results. AI is being used in efforts to make advertising more personalised, efficient, and interactive (Pemberton 2017), which advertisers claim will benefit users by providing them with more helpful, relevant, and entertaining ads. However, there is good reason to suspect that consumer and environmental protection is not being properly considered in the design and implementation processes of these technologies. 
Both advertising and AI can play huge roles in our fights against environmental degradation. From the potential efficiencies created by machine learning in energy distribution (c. f. Jungblut this issue), or $\mathrm{CO}_{2}$ removal (Rolnick 2019), to the ability of advertising to influence hearts and minds, both can, and should, be integrated into our collective toolkits for change. This paper, however, focuses on the major harms and issues caused by AI-enabled digital advertising, from a consumer and citizen perspective. [1]

\section{Advertising encourages unsustainable consumption}

"Materialistic values and goals, the consumption driving work a spend cycle, and the consumption of two illustrative products (beef and tobacco) are each a) encouraged by advertising and b) implicated in causing various forms of environmental damage" (Badverts 2020).

Advertising's main purpose is to sell products and services, which, unsurprisingly, puts it at loggerheads with Sustainable Development Goals (SDGs). Most higher income countries already consume more than the Earth can provide and regenerate in a year, to the point of five times the capacity of the earth in the USA, and 1.7 times the Earth's production capacity globally (Global Footprint Network 2019). The proliferation of smartphones allows advertisers to target customers at an increasing number of points during the day. This leads to strategies that seek to reach users at the exact "micro-moment" when they are uniquely receptive because they need or want something. However, despite the increase in the levels of sophistication in targeting, the jury is out as to whether this makes advertising more effective. What is concerning, however, is that $50 \%$ of the world's population is yet to come online (UNCTAD 2018) and when they do, they will be met with sophisticated advertising.

This persuasion power can also create great benefits and opportunities for the climate movement. Advertising generally involves attempting to create some form of attitude or behaviour change, or encourage a repeat behaviour, which can work both for or against climate action depending on how it is applied. Industry initiatives, such as the Advertising Association's Net Zero, highlight the potential opportunity in Action 5, which calls for: "Harnessing advertising's power to support consumer behaviour change” (Advertising Association 2020).

Indeed, professionalising communications and embracing the power of paid media to reach new audiences is extremely important for mainstreaming climate action. Many climate movements do not invest in advertising on social networks, meaning that their messages are only seen by their own fans and others in the environmental movement. Social media newsfeeds have been engineered to favour paid for content over organic, and the movement's understandable resistance to paying social networks is not mirrored by the opposition, who are demonstrably using advertising techniques to test and learn about which denial messaging works. Ironically, the climate movement is forced to increasingly embrace advertising to compete on a level playing field with those who work against them.

\section{Funding model for climate disinformation}

The WHO have declared society as in the middle of an "infodemic" (World Health Organisation 2020), a sentiment echoed by The UK Lords Select Committee on Democracy and Digital Technologies, who reported that we face a "pandemic of misinformation" that poses an existential threat to our way of life.

Key to this rise in mis- and disinformation is online advertising: advertising monetises online spaces. Failure to police where it is placed (and therefore, ultimately, what it funds) has created funding models for both hate and disinformation (Digital Shadows 2017). The famous "Pizzagate" scandal, for example, which spread spurious claims about Hillary Clinton during the 2016 US elections, involved Macedonian teenagers earning thousands of dollars a day from creating "fake news" sites which were funded through adverts and shared via social media (Metaxas/Finn 2019). In fact, The Global Disinformation Index estimates that at least 235 million USD in revenue is generated annually from ads running on extremist and disinformation websites (The Global Disinformation Index 2020), and studies from Avaaz (2019) found misinformation networks spanning at least five countries generated an estimated 3.8 billion views on Facebook over one year.

The issue here is that the advertising supply chain is opaque, and advertisers frequently do not know where on the web their advertising ends up. This creates a thriving market for fraud, hate and disinformation, as some actors exploit this lack of accountability. Disinformation also spreads online spaces faster than truth (Vosoughi et al. 2020). Reports by Avaaz (2020) found a disturbing dynamic: Climate disinformation was being funded by advertising, and then prioritised by AI-driven social media recommendation engines. These algorithms are designed to keep users on platforms for longer, and often prioritise content with high engagement rates, such as inflammatory disinformation.

Disinformation has also previously derailed multilateral agreements, making it concerning in the year of COP26. The 2018 UN Global Compact on Migration was undermined with a barrage of false information, perpetrated by far-right groups, which implied criminal sanctions for those who criticised migration, or even linked the Compact to EU policies (Read 2018) A media furore followed, with severe consequences for the Compact, as countries from Brazil to Israel pulled out, and the Belgian government collapsed amid infighting (Birnbaum 2018). The most chilling impact of this campaign was noted in New Zealand, where the handle of the gun used in the Christchurch massacre was found to be marked with the phrase “Here's your Compact on Migration" (Doyle 2019).

Steps have since been taken by social media platforms and advertisers to defund and deprioritise dangerous disinforma- 
tion, but solutions are not perfect, and it is incredibly important that the environmental movement engages with such issues. For more information on the different types of climate disinformation, including corporate greenwash, which has been well documented elsewhere.

\section{Digital advertising increases the carbon footprint of the internet}

Advertising is demonstrably increasing the internet's carbon footprint, and digital advertising's carbon footprint is increasing with the introduction of AI. Between one half and one third of internet traffic is fake, much of it linked to ad fraud. Advertising fraud can take several different forms, but each involves the creation of illegitimate, non-human traffic (bots) to deliberately attempt to extract money from advertising budgets (IAB UK 2017). Researchers estimate that the tech sector will contribute 3.0-3.6\% of global greenhouse emissions by 2020 (AI Now Institute 2019), and the estimated 2020 global footprint is comparable to that of the aviation industry (ATAG 2020). The electricity consumed to power online advertising generated approximately $60 \mathrm{MT}$ of $\mathrm{CO}_{2}$ in 2017 (Pärssinen et al. 2018). As digital advertising spend increases, so will its energy consumption.

The failure to halt growing levels of ad fraud is also increasing the amount of processing power and ad load online, increasing energy consumption and contributing to climate change. Adobe (2018) found that potentially $28 \%$ of web traffic came from bots or other non-human actors, and Botlab used a figure of $23 \%$ when estimating that ad fraud contributed approximately 13.87 million tonnes of $\mathrm{CO}_{2}$ to the atmosphere annually, roughly equivalent to the yearly emissions of Ghana (Botlab 2017).

\section{Policy interventions}

Tackling the issues created by online and AI-driven advertising requires bold and a long-term vision which enables the transition towards internet business models that are more rights-respecting, and environmentally friendly. Regulators must act fast because this is not just about the web as we know it. Advertising stands at the brink of widespread adoption of AI, but as an industry, has little appreciation of how to embed and account for human rights and environmental protection. Failure to change this thinking risks ingraining excessive data collection habits, inadvertent environmental degradation, and flawed metric-driven decision-making in our technologies and society for years to come. The time for a broader consideration of consumer protection, human rights and environmental impact within AI decision-making is now.

As online and offline environments become increasingly entwined, the harmful practices we see online risk sweeping into ever more connected offline spaces. Just as the home has become the latest frontier for data mining, so will public spaces. This risks the creation of worrying precedents - for surveillance,

\section{"Advertising is the \\ business model underpinning the web, and a key force in shaping the information environments which also shape public opinion."}

the erosion of non-commercial space, and a lack of accountability or transparency when things go wrong. Environmental protections and planning laws in many countries contain provisions such as the "Precautionary Principle" and requirements for investment in public services alongside development; these are designed to protect our commons from "free riders" and correct market failures and externalities. Yet few equivalents exist for digital and online spaces (Kaltheuner/Kingaby 2020). It is vital to protect our digital spaces in this way, as this is where people do so much more than communicate: they are where social movements form, where people learn about the news, and where we form perceptions of the world around us.

\section{Creating accountability for digital and physical supply chains}

Creating a more transparent advertising sector will bring about benefits for all. Since the 1990s, corporations have worked on their physical supply chains, mapping and improving them in line with international coalitions and standards such as ISO14001. An organisation's digital advertising supply chain should be subject to the same level of accountability, including suppliers and partners, and its governance integrated with their sustainability and consumer protection targets and obligations. Requirements for transparency and accountability in the digital advertising supply chain are already being enshrined in law, for example, France's Loi Avia requires companies to report their advertisement site lists every month to the public in a move christened the "Sleeping Giants" amendment (Jammi/Atkins 2020). A site list is a breakdown of the domains where ads have been served, which can be scrutinised by researchers. This public accountability creates an imperative for brands to ensure that their site lists do not include hate speech or disinformation. Mandating that all advertisers should declare the placement of their advertising in the public interest would contribute to defunding fraud and hate speech and creating the transparency which is needed to encourage collective responsibility for digital advertising supply chains. 


\section{"Creating a more \\ transparent advertising \\ sector will bring \\ about benefits for all."}

\section{Imposing restrictions on advertising high carbon industries}

In many places, advertising regulators and the platforms themselves, place restrictions on what advertisers can advertise, where, and to whom, to protect vulnerable groups, or discourage harmful behaviours such as gambling (Facebook 2018). However, evidence suggests that consistency of enforcement is key to these measures working, and there is strong evidence to suggest that enforcement and detection is inconsistent (UNCTAD 2018). Given the issues with corporate and state disinformation, it is recommended that:

- We develop legal definitions of disinformation, so that international standards and understanding can be reached.

- Those legal definitions to include climate denial and delay (Lamb et al. 2020) messaging, and information containing these definitions should be banned from monetisation across mediums and platforms, and from being prioritised in platform recommendation algorithms.

- High carbon industries should be classified as harmful, in the same way as tobacco and alcohol, and subject to restrictions on how and where they advertise.

\section{Investing in cross industry and civil society forums}

Underpinning all these recommendations is one for dialogue and forums to develop between digital rights and environmental protection groups, consumer protection experts, advertising stakeholders, and tech providers, many of whom will be grappling with similar issues from different perspectives. Planning must become proactive, rather than reactive. It is recommended that digital rights groups and consumer protection organisations engage with individual advertisers and advertising reform groups who can act as champions or sponsors of issues such as misinformation, and environmental sustainability, as well as advertising bodies themselves. Initiatives such as The Conscious Advertising Network form proof of concept.
These forums should be mediated and designed to:

- Create accountability, shared understanding and solutions to the issues of internet health - including new charters of online rights for citizens to escape surveillance capitalism.

- Include active participation from civil society groups directly affected by discrimination, or other market failures, to ensure that human rights have equal weight to corporate interest in discussions and solution building.

- Form new industry initiatives and guidelines that create leadership beyond regulation, and a proactive approach to assessing AI implementation against human rights.

- Suggest new regulatory interventions or call for enforcement where necessary.

- Identify and swiftly deal with the "unknown unknowns" which will undoubtedly arise as a result of the implementation of new technology.

\section{Conclusion}

Advertising is the business model underpinning the web, and a key force in shaping the information environments which also shape public opinion. With that great power should come great responsibility. However, the development and governance of the role advertising plays in shaping online spaces is being left to industry to decide on and to police. Legislative interventions are piecemeal, often unenforced, and lack an understanding of the role that advertising can play in the development of safe and citizen-focused online spaces. Only by considering the development of our online space in the same ways as we think of our offline ones - as something to be carefully stewarded, protected and planned - will we be able to make decisions regarding the responsibilities of the various actors involved in the funding and development of our online world. Systems thinking will be essential to avoiding further, greater online harms.

\section{Annotations}

[1] For more details on methodology, see Al Q Advertising, A Consumer Perspective (Kingaby 2020), on which this analysis is based.

[2] For more details, see the Change The Narrative report (Cheq, Media Bounty, Pulsar, The Conscious Advertising Network 2020), which contains further examples.

\section{References}

Advertising Association (2020): Ad Net Zero, All For None. www.adassoc.org. uk/ad-net-zero/

Al Now Institute (2019): Al and Climate Change: How they're connected, and what we can do about it. https://medium.com/@AINowlnstitute/ ai-and-climate-change-how-theyre-connected-and-what-we-can-do-aboutit-6aa8d0f5b32c

ATAG (2020): Facts \& Figures. www.atag.org/facts-figures.html Avaaz (2019): Why is YouTube Broadcasting Climate Misinformation to Millions? https://secure.avaaz.org/campaign/en/youtube_climate_ misinformation/

Avaaz (2020): How Facebook Can Flatten The Curve Of The Coronavirus Pandemic. https://avaazimages.avaaz.org/facebook_coronavirus_ misinformation.pdf 
Badverts (2020): Advertising's role in climate and ecological destruction. www.badverts.org/reports-and-publications

Birnbaum, M. (2018): Belgium's Ruling Coalition Collapses over U. N. Pact on Migration. www.washingtonpost.com/world/europe/belgiums-rulingcoalition-collapses-over-un-pact-on-migration/2018/12/09/e9740cc2-fbc911e8-a17e-162b712e8fc2_story.html

Capgemini (2019): Why addressing ethical questions in Al will benefit organisations. www.capgemini.com/gb-en/research/why-addressing-ethicalquestions-in-ai-will-benefit-organisations/

Cheq/Media Bounty/Pulsar/The Conscious Advertising Network (2020): Changing The Narrative, Smart Climate Campaigning In An Adversarial World. https://mediabounty.com/news/how-to-win-against-climatemisinformation/

Democracy \& Digital Technology Committee (2020): Lords Select Committee. www.parliament.uk/business/lords/media-centre/house-of-lordsmedia-notices/2020/jun-20/democracy-under-threat-from-pandemicof-misinformation-online-lords-democracy-and-digital-technologiescommittee/

Digital Shadows (2017): The Business Of Disinformation, A Taxonomy. https://resources.digitalshadows.com/whitepapers-and-reports/thebusiness-of-disinformation-fake-news

Doyle, J. (2019): New Zealand mosque attacker's plan began and ended online. www.reuters.com/article/us-newzealand-shootout-internetidUSKCNIQWIMV

Enberg, J. (2019): Global Digital Ad Spending 2019: Digital Accounts for Half of Total Media Ad Spending Worldwide. e-Marketer. www.emarketer.com/ content/global-digital-ad-spending-2019

Facebook (2018): Restricting Ads for Addiction Treatment Centers and Bail Bonds. www.facebook.com/business/news/restricting-ads-for-addictiontreatment-centers-and-bail-bonds

Forbrukerrådet (2020): OUT OF CONTROL: How consumers are exploited by the online advertising industry. https://fil.forbrukerradet.no/wp-content/ uploads/2020/01/2020-01-14-out-of-control-final-version.pdf

Global Footprint Network (2019): Earth Overshoot Day Stats. https://www. overshootday.org/content/uploads/2019/05/How_many_Earths_2019_ English.pdf

Guttmann, A. (2019): Al use in marketing - Statistics \& Facts. Statista. www.statista.com/topics/5017/ai-use-in-marketing/

Jammi, N./Atkins, C. (2020): France's new 'Sleeping Giants' law. https:// branded.substack.com/p/frances-new-sleeping-giants-law

Jobin, A./lenca, M./Vayena, E. (2019): The global landscape of Al ethics guidelines. In: Nature Machine Intelligence 1: 389-399.

Kaltheuner, F./Kingaby, H. (2020): An Adbreak For Europe. www.harrietkingaby.com/reports

Kingaby, H. (2020): AI \& Advertising, A Consumer Perspective. www.harrietkingaby.com/reports

Lamb, W./Mattioli, G./Levi, S./Roberts, J.T./Capstick, S./Creutzig, F./ Minx, J. C./Müller-Hansen, F./Culhane, T./Steinberger, J. K. (2020): Discourses of climate delay. In: Global Sustainability 3: 1-5.

Metaxas, P./Finn, S. (2019): Investigating the infamous \#Pizzagate conspiracy theory. https://techscience.org/a/2019121802/

Orlowski, J./Coombe, D./Curtis, V. (2020): The Social Dilemma. Netflix.

Pärssinen, M./Kotila, M./Cuevas, R./Phansalkar, A./Manner, J. (2018): Environmental impact assessment of online advertising. In: Environmental Impact Assessment Review 73: 177-200.

Pemberton, C. (2017): Simple Questions to Assess AI Risks and Benefits. www.gartner.com/en/marketing/insights/articles/simple-questionsto-assess-ai-risks-and-benefits

Read, C. (2018): Britain WILL SIGN United Nations proposal to make immigration human right. www.express.co.uk/news/politics/1053064/ United-nations-Global-Compact-for-Safe-Orderly-and-Regular-MigrationAlistair-Burt-italy

Rolnick, D. et al. (2019): Tackling Climate Change with Machine Learning. https://arxiv.org/pdf/1906.05433.pdf

The Global Disinformation Index (2020): Ad-funded COVID-19 Disinformation: Money, Brands, and Tech. https://disinformationindex.org/ research/
UNCTAD (2018): Working Group on Vulnerable and Disadvantaged Consumers, 3rd SESSION 9-10 July 2018. Intergovernmental Group of Experts on Consumer Law and Policy. https://unctad.org/meetings/ en/Presentation/WG\%20Vulnerable\%20and\%20Disadvantaged\%20 Consumers\%20.pdf

Vosoughi, S./Roy, D./Aral, S. (2018): The spread of true and false news online. Science 359/6380: 1146-1151.

World Federation of Advertisers (2018): WFA releases full version of Global Media Charter to reform digital ad ecosystem. https://wfanet.org/ knowledge/item/2018/06/21/WFA-releases-full-version-of-Global-MediaCharter-to-reform-digital-ad-ecosystem

World Health Organisation (2020): Managing the COVID-19 infodemic: Promoting healthy behaviours and mitigating the harm from misinformation and disinformation. Available online at: www.who.int/news/ item/23-09-2020-managing-the-covid-19-infodemic-promoting-healthybehaviours-and-mitigating-the-harm-from-misinformation-anddisinformation

Zuboff, S. (2015): Big other: surveillance capitalism and the prospects of an information civilization. In: Journal of Information Technology 30: $75-89$.
AUTHOR + CONTACT

Harriet Kingaby is a researcher working at the intersection between digital advertising technology, AI, human rights and climate change. She is currently the co-chair of the Conscious Advertising Network, and works at advertising agency, Media Bounty, on climate misinformation.

E-mail: hello@harrietkingaby.com, Tel.: +447547288236 